\title{
The Construction of Tourism Information Management Curriculum Based on the Analysis of Enterprise Demand Relevance
}

\author{
Xiaohui Wang ${ }^{a^{*}}$, Xin Wei ${ }^{b}$, Xiaoning Dou ${ }^{\mathrm{c}}$ and Kewei Lei ${ }^{\mathrm{d}}$ \\ School of leisure management, Xi'an Eurasia University, Xi'an, 710065, China \\ awxh2324@126.com, ${ }^{\mathrm{b}}$ weixin@eurasia.edu, ${ }^{\mathrm{C}}$ douxiaoning@eurasia.edu, ${ }^{\mathrm{d}}$ leikewei@eurasia.edu
}

Keywords: Enterprise demand; Relevance; Tourism information; Curriculum system

\begin{abstract}
Based on the method of correlation research, with the software SPSS, the author summarized the research data of tourism enterprises and analyzed the requirements of the tourism enterprises for the cultivation of tourism information talents. The results show that the correlation coefficient between the teaching method and the application level of tourism information technology is the largest, which is 0.563 . It is more consistent with the expectation of the teaching mode. Based on this result, the course system of tourism information management is constructed. It is composed by the basic course group, the skill curriculum group and the case group.
\end{abstract}

\section{Introduction}

The development of the information technology (IT) accelerates the growth of tourism economy and promotes the development of the tourism industry. The specific performance in the tourism enterprise network construction, management of IT, website construction, information service, online destination information network construction, tourism enterprise customer relationship management, online marketing, tourism information connotation and extension etc[1-3]. But at present, China's tourism education mainly attention to the management of tourism enterprises, while ignoring the change of era and the development of tourism industry under the condition of network economy, directly affect the students' practical ability and innovative spirit[4-6]. Therefore, the development of tourism information education has become the inevitable requirement of future tourism management personnel training.

Tourism information management course is a combined and comprehensive subject, it relates to tourism enterprise management, information technology, software development, planning, geography and other disciplines of knowledge. The knowledge update speed, the complex theory, multimedia practice and other issues challenges the curriculum design.

\section{Research Methods}

In December 2016, the author carried on the investigation to the staff of Xi'an tourism industry. Methods this study used questionnaire and on-the-spot interviews, the questionnaire asked respondents to $1-5$ grade for each index score, 5= "strongly agree",4= "agreed," $3=$ "neutral", $2=$ "no", $1=$ "is opposed to", so as to show their expression of reply.

There were 6 projects in the questionnaire. A total of 30 questionnaires were distributed, and a total of 30 questionnaires were recovered, and the effective questionnaires were collected by the questionnaire. The questionnaire recovery rate was $100 \%$, and the interviews were conducted with the managers of the tourism enterprises in order to get a lot of information about the.

\section{Questionnaire Analysis and Establishment of Regression Equation}

Using the social statistics software Spss13.0, the reliability of the questionnaire was analyzed firstly and the Baja coefficient of the questionnaire was 0.875 proved to have a high intrinsic reliability.

The questions mainly involve 6 problems with improving the application level of the tourism information technology. It includes the courses, teaching methods, training opportunities, 
participates in projects, training conditions and the internship opportunities. The six factors are $x_{1}, x_{2}, x_{3}, x_{4}, x_{5}, x_{6}$ and the skill upgrading is $y_{\text {[7]. }}$

In order to reflect the statistical relationship between the independent variable and the dependent variable, the linear relationship between the two variables must be checked. Statistics are used in the test:

$$
F=\frac{\sum_{i=1}^{n}\left(\hat{y}_{i}-\bar{y}\right)^{2}}{\sum_{i=1}^{n}\left(y_{i}-\hat{y}_{i}\right)^{2} /(n-2)} \quad(\mathrm{n}=30)
$$

Supposing $H_{0}: \beta_{1}=0$, there is no significant difference between regression coefficients and zero. For the given significant level $a=0.05$, calculated the $\mathrm{F}$ value, the probability of $x_{1}, x_{2}, x_{3}, x_{4}, x_{5}$ and $x_{6}$ is less than 0.05 . Then the null hypothesis should be rejected. So these factors and the economic growth has a significant linear relationship, that is $y=\beta_{0}+\beta_{1} x_{1}+\beta_{2} x_{2}+\beta_{3} x_{3}+\beta_{4} x_{4}+\beta_{5} x_{5}+\beta_{6} x_{6}$.

Using the multiple linear regression method, the parameter estimation of the equation could get finally. Put the observed data into the above equation, the regression equation is:

$$
y=0.875+0.287 x_{1}+0.563 x_{2}+0.267 x_{3}+0.276 x_{4}+0.033 x_{5}+0.126 x_{6}
$$

In order to test whether the regression effect is good, the cumulative probability plot is used to test. The results show that the cumulative probability points along the diagonal distribution of the more close to the diagonal chart shows that the better regression. It can be seen that the data distribution is good and the fitting degree is high (see Fig. 1).

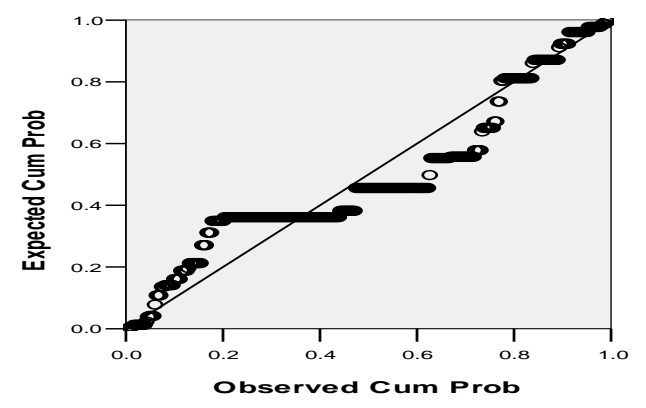

Figure 1. Normalized residual normal probability plot

By the regression equation, correlation coefficient method and teaching application level of tourism information technology, 0.563 , this also with the enterprise to the school's teaching mode is consistent with expectations, the tourism enterprises agreed that more enterprises welcome active thinking, good at expressing their own students, and be good at cultivating students' communication ability. The correlation coefficient between the curriculum and the project participation is closer, respectively, 0.287 and 0.276 , indicating that in the curriculum, as much as possible to set up students to participate in the link to enhance the ability of students.

\section{Tourism Information Management Curriculum System Construction and Suggestions}

The Construction of Curriculum System. Based on the existing tourism information curriculum theory teaching system and teaching contents of research and analysis, can determine the way to enhance tourism information application ability, which is the foundation for the construction of tourism information management curriculum system. Combined the research teaching method and the interactive teaching mode replaced the traditional injection teaching method. The research type teaching method is mainly embodied in the following two aspects: the 
tourism information competition and the tourism information entrepreneurship [8,9]. In general, the tourism information management curriculum system can be summarized as three parts: "basic course group + skill curriculum group + case curriculum group", and its architecture is shown in figure 2 .

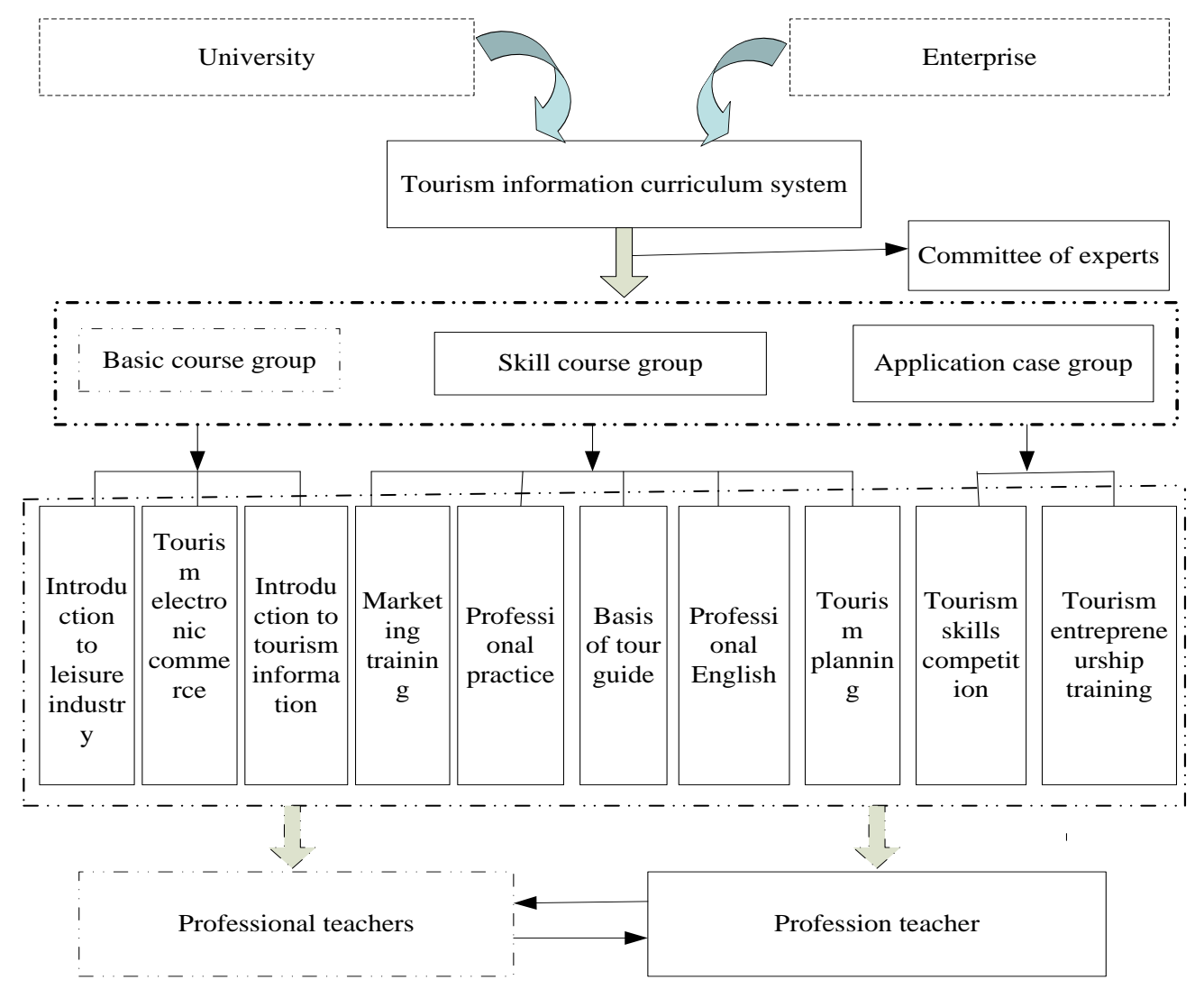

Figure 2. Tourism information management curriculum system

The Implementation of the Curriculum System. Because tourism information teaching has the characteristics of knowledge, systematic, occupation and application, in order to ensure the smooth implementation of the curriculum, the face to emphasize the internationalization in the teaching mode of theory and practice courses include two categories, pay attention to practice, practice teaching is more than theoretical classes, flexible teaching methods assessment methods varied, we must strengthen the training the use of hardware facilities and technology mode and improve the tourism information talents[10,11].

First, established the professional training room and enhanced the practical teaching links. For the tourism information teaching, we need to put into the computer terminal and mobile terminal training equipment, let the students to contact the most real business environment; again, supporting the simulation of the operating environment, enhance the actual effect of the course. A perfect training room of tourism enterprises makes a useful complement to tourism marketing courses; finally, the practical teaching mode, enhance the market competition ability. In order to improve the students' consciousness of innovation and entrepreneurship, we need to increase the actual content in the daily curriculum, and achieve the teaching design and purpose of the theoretical research from the classroom to the market.

\section{Conclusions}

In a word, in order to better training of tourist information, in addition to change the teaching idea, the advanced hardware facilities must further improve and perfect, so as to better enable students to master the skills, enhance the ability to enhance their competitiveness. 


\section{Acknowledgements}

This work was partly supported by the Social science project of Shaanxi Province (2016R022) and Curriculum reform project of School of leisure manageent.

\section{References}

[1] Fuchs M, Höpken W, Mirski P, et al. tourism Curriculum Development: A Destination Management Organization Perspective [J]. Information \& Communication Technologies in Tourism, (2007), p. 523-534.

[2] Ritchie J R B. Design and Development of the Tourism/Hospitality Management Curriculum [J]. Tourism Recreation Research, vol. 20 (2014) N0. 2, p.7-13.

[3] Bird J, Mortel T V D, Holt J, et al. Academics' perceptions of continuous and collaborative curriculum review: An Australian case study [J]. Journal of Hospitality \& Tourism Management, vol.24 (2015), p. 18-24.

[4] Porcaro P A, Jackson D E. Curriculum Design of a Flipped Classroom to Enhance Haematology Learning [J]. Journal of Science Education and Technology, vol.25 (2016) No. 3, p. 345-357.

[5] Hernández L, Baladrón C, Aguiar J M, et al. Experimental Analysis of the Input Variables' Relevance to Forecast Next Day's Aggregated Electric Demand Using Neural Networks[J]. Energies, vol.6 (2013), No.6, p. 2927-2948.

[6] Brooman S, Darwent S, Pimor A. The student voice in higher education curriculum design: is there value in listening? [J]. Innovations in Education and Teaching International, vol. 246(2015) No. 6, p. 1-12.

[7] Berger A, Shen M Z, Hierner M R. 3D imaging software for knee replacement surgery.(Software \& Information Management Systems)[J]. Chinese Journal of Hand Surgery, vol.16 (2000) No.1, p. 233-240.

[8] Shyju P J. Curriculum Development - Need of Restructuring Tourism Management Courses at Undergraduate Level[C]// Hostocon. (2016).

[9] Bird J, Mortel T V D, Holt J, et al. Academics' perceptions of continuous and collaborative curriculum review: An Australian case study [J]. Journal of Hospitality \& Tourism Management, vol.2 (2015), p.18-24.

[10] Qin. Knowledge management system for e-tourism curriculum development /Shiyu Qin [J]. Heart, vol.102 (2016), No.6, p. 53-55.

[11]Zhang P, Zhou T, He L, et al. Dispersion of multi-walled carbon nanotubes modified by rosemary acid into poly(vinyl alcohol) and preparation of their composite fibers[J]. Rsc Advances, vol.5 (2015) No. 68, p. 55492-55498. 